\title{
ASPECTOS HIDROLÓGICOS NA DESEMBOCADURA DA LAGUNA DOS PATOS, RS
}

\author{
CARLOS HARTMANN* \& CARLOS A. F. SCHETTINI**
}

\begin{abstract}
HYDROLOGICAL ASPECTS AT PATOS LAGOON MOUTH, BRAZIL. The southern portion of Patos Lagoon corresponds to a large estuarine environment The hydrology and water quality in this area are conditioned by its morfology, wind pattern (direction and intensity) and freshwater runoff in the drainage basin. This paper presents the results of nineteen (19) periodical cruises (May/1982 to December/1983), designed to measure in situ water quality parameters. Suspended matter showed irregular behavior, associated to salt water intrusions and fluvial flow. Salinity data based on transversal sections, demonstrated a seasonal trend. Besides the four estuarine circulation models described in the literature, exceptional circulation patterns were identified. It is noticeable that the local hydrology can change rapidly, in response to local meteorological conditions.
\end{abstract}

Keywords: Estuary, suspended matter, water quality, Patos Lagoon., Rio Grande do Sul, Brazil.

\begin{abstract}
RESUMO A extremidade sul da Laguna dos Patos é na maior parte do ano um ambiente estuarino. A hidrologia e a qualidade da água nesta região estão condicionadas à sua morfologia, às pequenas amplitudes de maré $(0,47 \mathrm{~m}$ em média/ano) e à ação dos fatores meteorológicos (vento e precipitação nas bacias hidrológicas). Neste trabalho, são apresentados os resultados da investigação de 19 campanhas periódicas (maio de 1982 a dezembro de 1983) sobre levantamentos in situ da qualidade da água. Concentrações do material em suspensão tiveram comportamento irregular, associado às intrusões de água salgada, à ressuspensão de sedimentos e, principalmente, com p aporte de água doce. Análises de seções transversais e ao longo do canal da salinidade mostram que as situações hidrológicas encontradas para a circulação têm um comportamento sazonal, apresentando os quatro modelos de circulação estuarina discutidos na literatura, além de casos excepcionais. Ressalta-se que a hidrologia da região pode mudar rapidamente, em função das condições meteorológicas locais.
\end{abstract}

Palavras-chaves: Estuário, material em suspensão, qualidade da água, Laguna dos Patos, Rio Grande do Sul, Brasil.

INTRODUCÃ̃O Regiões costeiras são muito suscetíveis a mudanças de ordem geral, determinadas pela ação de marés e ventos, em poucas toras ou dias. As mudanças climáticas sazonais que ocorrem sobre as áreas continentais adjacentes causam mudanças de temperatura e padrões de ventos, além de precipitações e descargas dos rios.

$O$ extremo sul da Laguna dos Patos (Fig. 1) pode ser enquadrado como sendo um estuário de planície costeira, apresentando algumas peculiaridades que o tomam característico. Arnason (1984) considera que, fisiograficamente, os estuários variam consideravelmente, e um tipo importante é o denominado estuário de planície costeira, comum ao longo das costas do Atlântico Norte. Na maior parte do ano, na região sul da Laguna dos Patos, é observado um comportamento hidrológico tipicamente estuarino. Entretanto, as características relacionadas à morfologia, amplitudes de maré $(0,47 \mathrm{~m}$ em média por ano), e a ação constante dos fatores meteorológicos, locais e sazonais, principalmente dos ventos e da precipitação nas bacias hidrográficas das Lagunas dos Patos e Mirim (Fig. 1), estabelecem condições especiais que influenciam os parâmetros ambientais e hidrológicos.

As investigações conduzidas na área da desembocadura durante o Projeto Material em Suspensão, por Hartmann et al (1985) Fase I, Hartmann (1985) Fase II, e Paim \& Moller (1986) Fase III, permitiram relacionar as variações hidrológicas com os modelos básicos de circulação estuarina descritos por Pritchard (1967), e já relatados por Moller et al (1984), Hartmann (1988), e Hartmann (1989). Este trabalho tem por objetivo fazer considerações sobre os aspectos hidrológicos que ocorrem na região da desembocadura da Laguna dos Patos, tendo por base os resultados obtidos durante a Fase $n$ deste projeto.
Condicionantes climáticas e hidrológicas Os fenômenos atmosféricos da região lagunar da Planície Costeira do Rio Grande do Sul influenciam decisivamente o seu sistema hidrológico. Para que se possa obter um melhor entendimento da sua circulação, é necessária uma análise detalhada dos sistemas atmosféiicos, bem como das relações destes com os fenômenos hidrológicos (Paz 1984).

O clima da região é do tipo subtropical úmido, sendo bastante dominado pela massa tropical marítima. A temperatura média anual é de $17,5^{\circ} \mathrm{C}$, tendo média máxima de $22,9^{\circ} \mathrm{C}$ e mínima de $12,9^{\circ} \mathrm{C}$. A média pluviométrica anual é de 1.300 $\mathrm{mm}$ no litoral (Delaney 1965).

O sistema hidrológico do Rio Grande do Sul é composto por duas bacias de drenagem principais: a Bacia do Uruguai, cujas águas vão ter no estuário do Rio da Prata, e o Sistema Lacustnno, que predomina na porção leste do Estado.

O Sistema Lacustnno ou Bacia do Sudeste divide-se em dois subsistemas, sendo o mais importante o da Laguna dos Patos, onde é debitada a vazão do Complexo do Guaiba, e o da Laguna Mirim - as quais, juntas, apresentam uma bacia hidrográfica de aproximadamente $199.000 \mathrm{~km}^{2}$, tendo como única ligação com o oceano o Canal do Rio Grande (Fig. 1).

O Complexo Guaiba é formado pelos Rios Jacuí, Sinos e Caí, desaguando na parte norte da Laguna dos Patos, com vazões variando entre $45 \mathrm{~m}^{3} / \mathrm{s}$ no verão a $25.000 \mathrm{~m}^{3} / \mathrm{s}$ no inverno. Na parte média, a sub-bacia mais importante é a do Rio Camaquã, com vazões entre $6 \mathrm{~m}^{3} / \mathrm{s}$ (verão) a $5.300 \mathrm{~m}^{3} / \mathrm{s}$ (primavera) (Herz 1977).

O escoamento do Complexo Mirim se faz através do Canal do São Gonçalo na parte mais ao sul da Laguna dos Patos, na desembocadura, com vazão média de $566 \mathrm{~m}^{3} / \mathrm{s}$ (DNAEE 1974).

\footnotetext{
* Laboratório de Oceanografia Geológica, Departamento de Geociências, Fundação Universidade do Rio Grande, Caixa Postal 474, CEP 96200, Rio Grande, RS, Brasil

** Bolsista de Iniciação Científica
} 


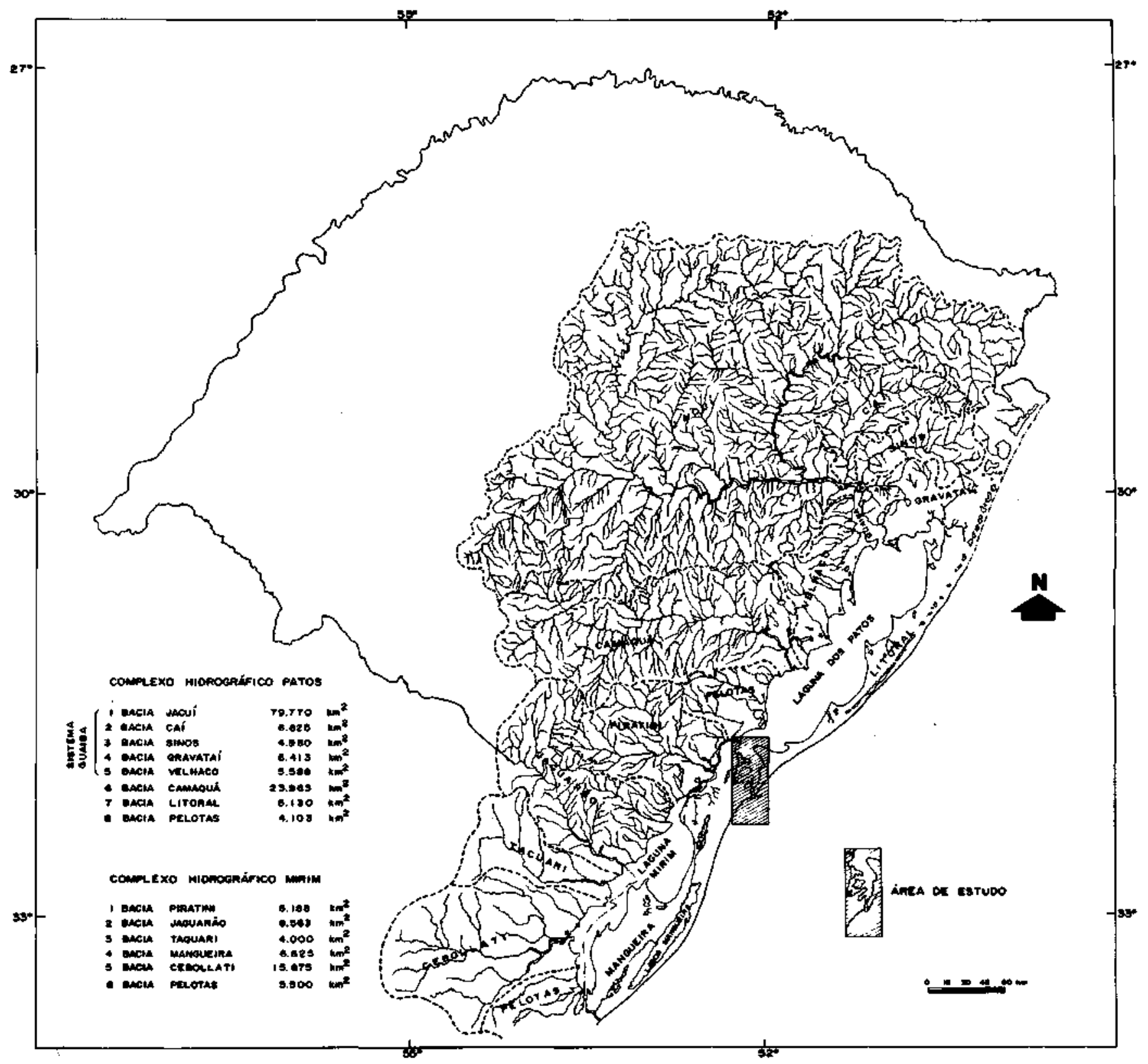

Figura 1 - Localização da área de estudo e bacias hidrográficas Patos e Mirim Figure 1 - Location of the study area and hydrografic basin of Patos and Mirim lagoons

Visto que a desembocadura está em uma região de baixa amplitude de maré, esta se faz discreta como fator condicionante da circulação, sendo mais importante os regimes de ventos e a pluviometria cujas combinações promovem situações variadas, principalmente na região da desembocadura.

Na figura 3 estão representadas a vazão média diária do Complexo Guaíba e as datas dos cruzeiros para o período de 1982 a 1983. Este representa, para o sistema, aproximadamente $58 \%$ do volume de água que ali aporta, sendo o restante oriundo da Bacia do Camaquã $(13,2 \%)$ e do Sistema Mirim $(28,8 \%)$ (Bordas et al. 1984). Na falta de dados globais de vazão no canal de Rio Grande, devido à complexidade do fluxo bi-direcional, os dados acima são utilizados como base para indicar os níveis da laguna e de vazão na desembocadura, possibilitando, dessa forma, inferir sobre as condições de circulação nos períodos de amostragem e associá-los à qualidade da água, (Moller et al. 1989). O tempo médio de defasagem do fluxo entre o Complexo Guaíba e a desembocadura é citado como sendo de 23 dias (Herz 1977).

MATERIAL E MÉTODOS Os dados apresentados neste trabalho foram obtidos na região da desembocadura da Laguna dos Patos (Fig. 1), por meio de uma campanha de amostragem, no período de maio de 1982 a dezembro de 1983 , totalizando 19 cruzeiros utilizando a lancha Oc. Larus, da Fundação Universidade do Rio Grande - FURG.

As amostragens in situ foram realizadas em 30 pontos, localizados principalmente em três seções transversais, em dois e três níveis e, superficialmente, ao longo dos canais principais (Fig. 2).

Nas estações, eram medidas a salinidade e a temperatura (termosalinômetro de indução, com eletrodo Beckmaim; refratômetro AO, modelo 14419); transparência (disco de Secchi); e velocidade e direção de correntes (correntômetro 
Hidrocean, modelo IRFE). Localmente, eram feitas observações do vento (direção e velocidade) com anemômetro portátil (Hidrocean modelo VAVAL S-01).

Amostras de água foram coletadas em cada ponto na superfície, no meio e no fundo (garrafa horizontal modificada de Otman 1964), em pontos onde a profundidade era superior a $3 \mathrm{~m}$, e em dois níveis (superfície e fundo), quando a profundidade era inferior.

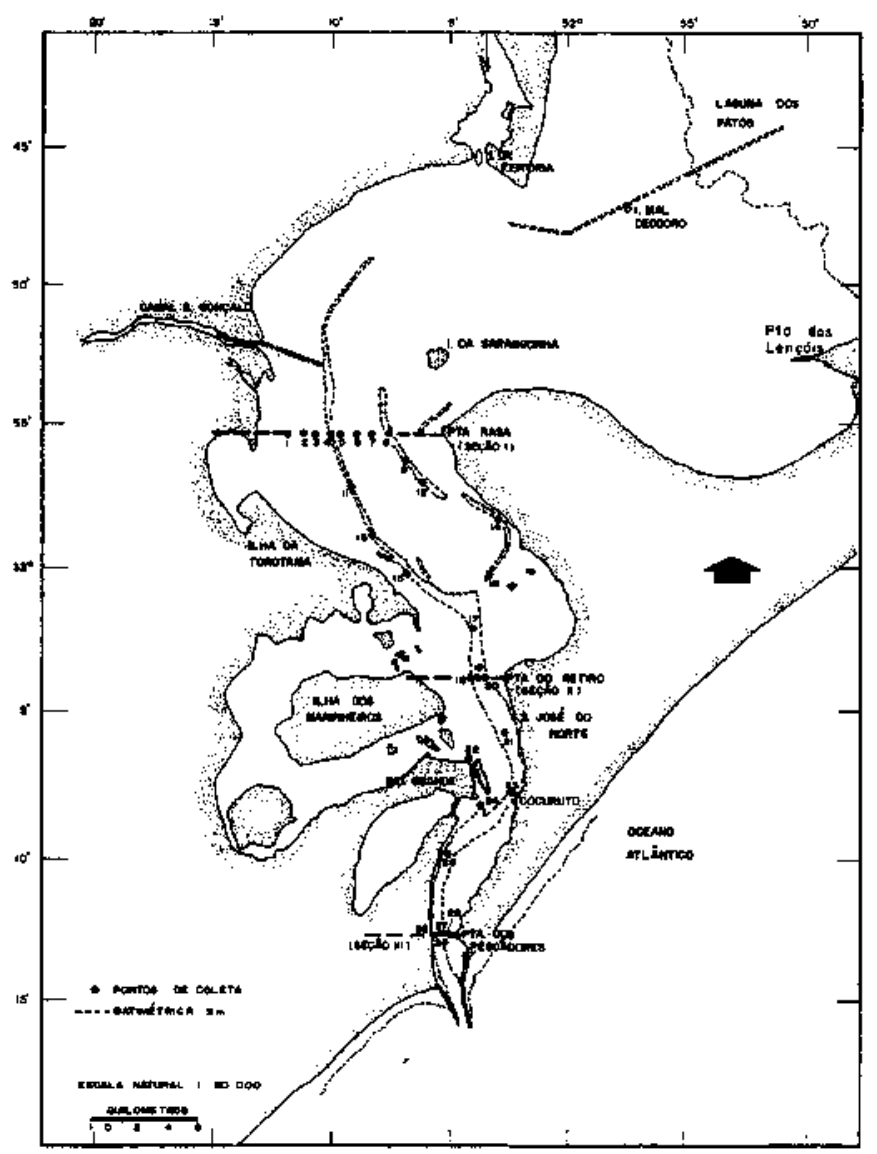

Figura 2 - Localização dos pontos de amostragem Figure 2 - Samples location

O posicionamento das estações teve por base as cartas náuticas da Diretoria de Hidrografia e Navegação (DHN) na escala apropriada, bóias e faroletes existentes ao longo dos canais de navegação, profundidade local (ecobatímetro SIMRAD EY) e radar da embarcação. Com isso, foi possível identificar com a precisão requerida todas as amostragens feitas no período de dois anos.

Análises de Laboratório A quantificação dos totais do material em suspensão (MS) das amostras de água era obtida pela filtração com auxílio de bomba de vácuo através de filtros pré-pesados de acetato de celulose $(0,45 \mu \mathrm{m}$ de poro e $45 \mathrm{~mm}$ de diâmetro), sendo o resultado calculado pela diferença de peso do filtro antes e após a filtração em $\mathrm{mg} / 1$. Para pesagem, foi utilizada uma balança analítica Metier H-54 com $0,01 \mathrm{mg}$ de precisão.

RESULTADOS E DISCUSSÃO A desembocadura da Laguna dos Patos é, de todo o complexo lagunar do Rio Grande do Sul, a feição mais importante, por caracterizar um sistema estuarino na maior parte do ano. Esta é uma das muitas razões para que nessa área sejam feitas pesquisas que permi- tam obter o entendimento das condições hidrológicas e da qualidade da água, como discutidos neste trabalho.

As investigações realizadas nessa região, ao longo dos últimos anos, em diversas áreas de pesquisa (Calliari 1980, Kantin 1982, Asmus 1984, Hartmann 1988, entre outros), demonstraram sua importância e, ao mesmo tempo, a complexidade do comportamento hidrodinâmico, inerente às regiões costeiras.

Como mencionado anteriormente, a configuração morfológica e as condicionantes meteorológicas determinam para a área condições próprias com mudanças radicais em pequenos intervalos de tempo (Paz 1984).

São identificados na desembocadura os quatro modelos básicos de circulação estuarina descritos por Cameron \& Pritchard (1963) e por Pritchard (1967). Estes autores consideram que estuários de planície costeira podem ser divididos em quatro tipos principais, diferindo um do outro no padrão de circulação de densidade, na intensidade de estratificação e na homogeneidade em extensão lateral da salinidade. Entretanto, podem ocorrer na área situações de vazão excepcional, quando os totais de precipitação estão acima do normal nas bacias versantes, conjuntamente com ventos do quadrante norte, acarretando uma perda de identidade estuarina na desembocadura, sendo encontrado, então, um deslocamento unidirecional em sentido de jusante, tipicamente fluvial, representado por A2 (Tab. 1).

Tais situações foram observadas e estão representadas nos cruzeiros $14,15,16$ e 18 , correspondendo a períodos de inverno e primavera (Fig. 3). Por ocasião dos cruzeiros $14 \mathrm{e}$ 15 , foram observadas vazões no Guaíba da ordem de 4.000 e $10.000 \mathrm{~m}^{3} / \mathrm{s}$, respectivamente. Estas razões de fluxo, associadas a ventos do quadrante norte, impedem a intrusão salina nas camadas inferiores do estuário (Paim \& Moller 1984). Embora a mesma situação também ocorra nos cruzeiros 16 e 18 , esta não é devida exclusivamente ao aporte do Complexo Guaíba e aos fatores meteorológicos, mas também à contribuição do complexo hidrográfico Mirim, a qual está representada na figura 3 . Nestes casos, cruzeiros 16 e 18 , o tempo de atuação do vento no sentido do eixo da laguna (NE-SW), comuns nessa época do ano, é o principal fator condicionante das razões de fluxo elevadas que se observam na desembocadura, somado aos aportes fluviais. Caso o somatório de todos estes fatores resulte em uma razão de fluxo à jusante superior a $4.000 \mathrm{~m}^{3} / \mathrm{s}$, ocorre a expulsão da água salgada, não permitindo a intrusão da cunha salina na desembocadura (Paim \& Moller 1984).

Em outras situações observadas de intenso fluxo fluvial, acima de $4.000 \mathrm{~m} / \mathrm{s}$ para o sistema Guaíba, não ocorre a expulsão dos sais da desembocadura devido ao equilíbrio estabelecido por ventos do quadrante sul, que podem gerar uma maré meteorológica superior a um metro de altura na região costeira adjacente, diminuindo a diferença entre os níveis do interior da laguna e da bacia receptora.

A morfologia da desembocadura influencia a extensão na qual a maré invade a laguna, e a salinidade varia, em parte, por isso. Assim, o limite norte da região estuarina é apontado como sendo a linha que une a Ponta dos Lençóis à Ponta da Feitoria, aproximadamente $80 \mathrm{~km}$ a montante da barra (Closs 1962, Calliari 1980). Entretanto, pode extender-se para o interior da laguna até sua porção intermediária (aproximadamente $200 \mathrm{~km}$ ), em casos de estiagem prolongada associada com ventos provenientes do quadrante sul - condições estas que favorecem a entrada de água salgada, determinando situações de estuário homogêneo (tipo $\mathrm{Al}$ ), encontrado nos cruzeiros 1, 2 (outono) e 9 (verão). As situações intermediárias de estuário parcialmente estratif içado foram observadas nos cruzeiros 10,11,13 (outono), 17 e 19 (primavera); situações de fluxo fluvial mais elevado gerando uma forte estratif icação, verificada na Ponta dos Pescadores, caracterizando uma circulação do tipo cunha salina, foram observadas nos cruzeiros 4, 5 (inverno), 6, 7, 8 (primavera) e 12 (outono). 


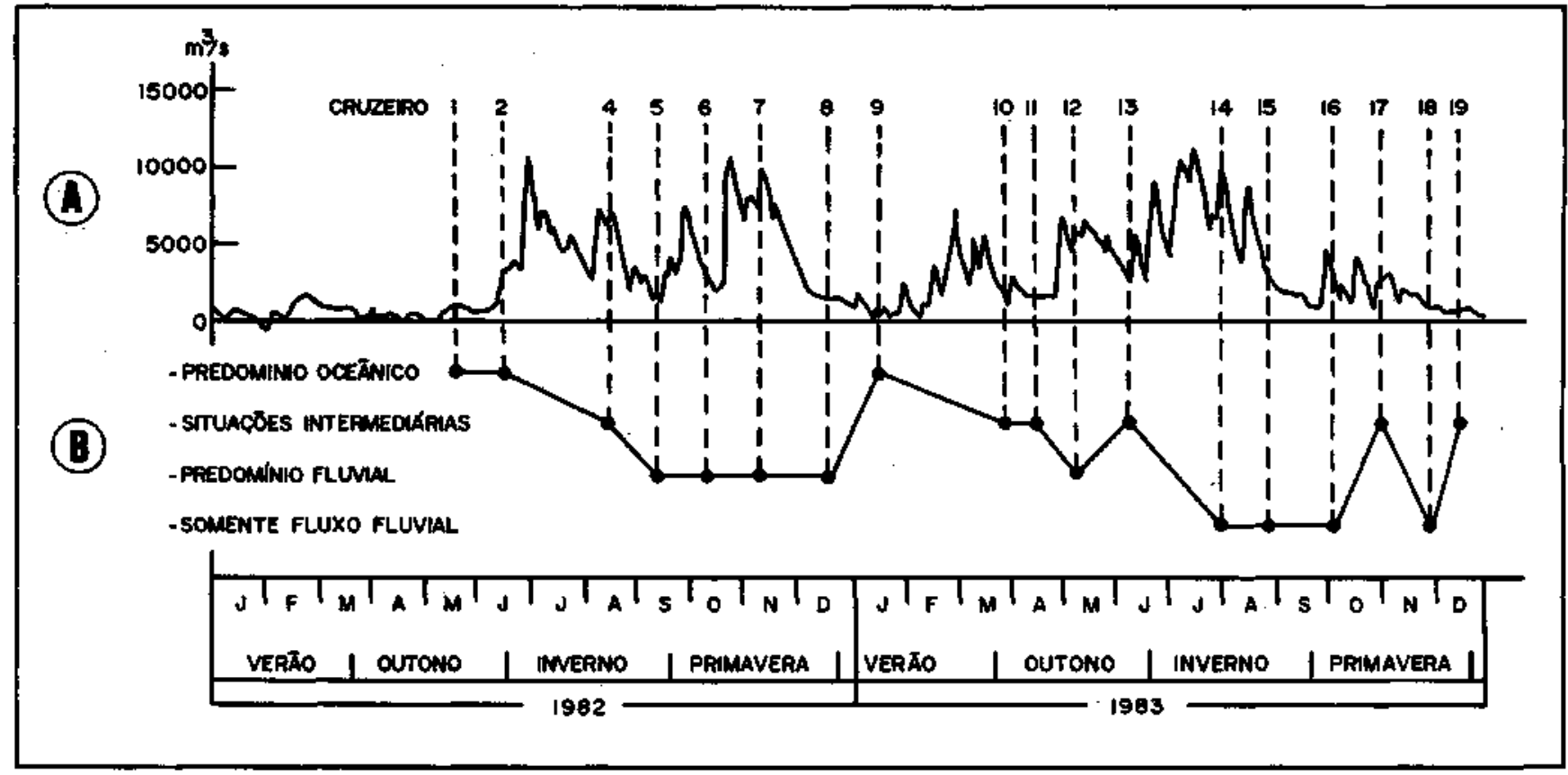

Figura 3 - Vazão diária do Sistema Guaiba (A) e situação dinâmica observada na desembocadura (B) para os anos 1982 e 1983

Figure 3 - Daily runoff of Guaiba System (A) and dynamical conditions observed at the lagoon mouth (B) for years 1982 and 1983

Tabela 1 - Cruzeiro, tipo de estuário (segundo Cameron \& Pritchard 1963) e salinidade nos perfis transversais. Superfície (S) e Fundo $(\mathrm{F}) .(*)$ condições adversas impediram amostragem

Table 1 - Cruises, estuarine circulation pattern (according Cameron \& Pritchard 1963) and salinity on transversal profiles. Surface (S) and bottom (F). (*) no sampling (stormy conditions)

\begin{tabular}{|c|c|c|c|c|c|c|c|c|}
\hline \multirow{3}{*}{ CRUZEIRO } & \multirow{3}{*}{$\begin{array}{l}\text { PERTODO DE } \\
\text { AMOSTRAGEM }\end{array}$} & \multirow{3}{*}{$\begin{array}{c}\text { ESTUÁRIO } \\
\text { TIPO }\end{array}$} & \multicolumn{6}{|c|}{ SALINIDADE } \\
\hline & & & \multicolumn{2}{|c|}{ SEÇAO 1} & \multicolumn{2}{|c|}{ SEÇAO 2} & \multicolumn{2}{|c|}{ SEÇAO 3} \\
\hline & & & $\mathbf{s}$ & F & $\mathbf{S}$ & $\mathbf{F}$ & $\mathbf{s}$ & $\mathbf{F}$ \\
\hline MS 1 & $18-19 / 05 / 82$ & $\overline{A 1}$ & 34,00 & 35,00 & 34,48 & 34,62 & 34,20 & 34,30 \\
\hline MS 2 & $15-16 / 06 / 82$ & A1 & 30,00 & 30,20 & 30,60 & 30,63 & 30,50 & 30,64 \\
\hline *MS 3 & $12-13 / 07 / 82$ & S/DADOS & - & - & - & - & - & - \\
\hline MS 4 & $16-17 / 08 / 82$ & B & 1,20 & 2,40 & 1,40 & 1,80 & 3,00 & 23,00 \\
\hline MS 5 & $13-14 / 09 / 82$ & D & 0,66 & 1,40 & 0,98 & 0,99 & 1,24 & 26,30 \\
\hline MS 6 & $11-12 / 10 / 82$ & D & 0,00 & 0,00 & 0,00 & 0,00 & 0,00 & 20,30 \\
\hline MS 7 & $11-12 / 11 / 82$ & D & 0,00 & 0,00 & 0,30 & 1,30 & 1,30 & 20,30 \\
\hline MS 8 & $21-22 / 12 / 82$ & C & 0,00 & 0,00 & 0,00 & 0,00 & 0,80 & 15,00 \\
\hline MS 9 & $17-18 / 01 / 83$ & A1 & 31,60 & 31,70 & 32,20 & 32,90 & 32,50 & 32,90 \\
\hline MS 10 & $30-31 / 03 / 83$ & B & 0,00 & 1,00 & 1,80 & 18,00 & 7,80 & 30,00 \\
\hline MS 11 & $18-19 / 04 / 83$ & B & 1,90 & 8,00 & 4,70 & 6,30 & 9,80 & 10,90 \\
\hline MS 12 & $23-24 / 05 / 83$ & D & 1,00 & 1,10 & 0,80 & 1,10 & 1,00 & 29,00 \\
\hline MS 13 & $10-11 / 06 / 83$ & B & 0,70 & 2,90 & 3,80 & 15,40 & 14,00 & 15,00 \\
\hline MS 14 & $02-03 / 08 / 83$ & A2 & 0,00 & 0,00 & 0,00 & 0,00 & 0,00 & 0,00 \\
\hline MS 15 & $29-31 / 08 / 83$ & A2 & 0,00 & 0,00 & 0,00 & 0,00 & 0,00 & 0,00 \\
\hline MS 16 & $05-06 / 10 / 83$ & $\mathbf{A} 2$ & 0,00 & 0,00 & 0,00 & 0,00 & 0,00 & 0,00 \\
\hline MS 17 & $31 / 10-01 / 11$ & B & 0,00 & 0,00 & 16,00 & 27,00 & 26,00 & 27,00 \\
\hline MS 18 & $29-30 / 11 / 83$ & A2 & 0,00 & 0,00 & 0,00 & 0,00 & 0,00 & 0,00 \\
\hline MS 19 & $16-17 / 12 / 83$ & C & 0,00 & 28,00 & 5,00 & 28,00 & 24,00 & 28,00 \\
\hline
\end{tabular}

Padrões de circulação observados Bowden (1967) considera as correntes de maré em relação ao fluxo do rio como sendo o fator básico na determinacão do tipo de circulação estuarina. Entretanto, dois outros fatores influenciam nesta situação, são eles: 1. dimensões físicas da área estuarina $\mathrm{e}, 2$. força de coriolis.

Dos fatores acima mencionados, para a região em estudo, as dimensões e a morfologia são as mais importantes. A maré, 
apesar de apresentar alguma influência sobre o sistema, onde se estima que o sinal médio no nível da água seja da ordem de 10 a $15 \mathrm{~cm}$, o que corresponde de 8 a $10 \%$ da variação total (Hartmann 1988), é em geral mascarada pela ação do vento. Neste estudo, não são considerados os efeitos da força de coriolis devido a fisiografia estreita da área.

O fluxo de entrada de água dos rios para dentro dos sistemas estuarinos varia muito, e as condições de estuários (tipos) se modificam em função disto, sendo então necessários estudos sobre estas variações (Bowden 1967).

Considerando as variações médias da salinidade de superfície e de fundo, observadas nas secões transversais, a desembocadura foi caracterizada para cada período amostrai, como apresentado na tabela 1 .

Os diferentes padrões de circulação estuarina observados estão relacionados com a época do ano ou associados às variações mais bruscas, como já citado por Moller et al (1984).

Observam-se, na tabela 1 , os quatro modelos citados por Cameron \& Pritchard (1963), representados na figura 4, tendo por base a variação da salinidade ao longo do eixo do canal principal. As situações excepcionais (tipo A2) não estão representadas.

Considerações sobre a hidrologia e a distribuição do material em suspensão Rusnak (1967) considera três tipos de bacias para o suprimento de sedimento: 1. Bacias de acumulação direta (positiva), onde os sedimentos acumulados são provenientes do continente; 2 . Bacias de acumulação neutra, quando não existe acumulação; 3 . Bacias de acumulação inversa, onde os sedimentos acumulados são provenientes do oceano por erosão local.

cr. ws 1

EstuARIO: TIPO irertiealmente misfuradol

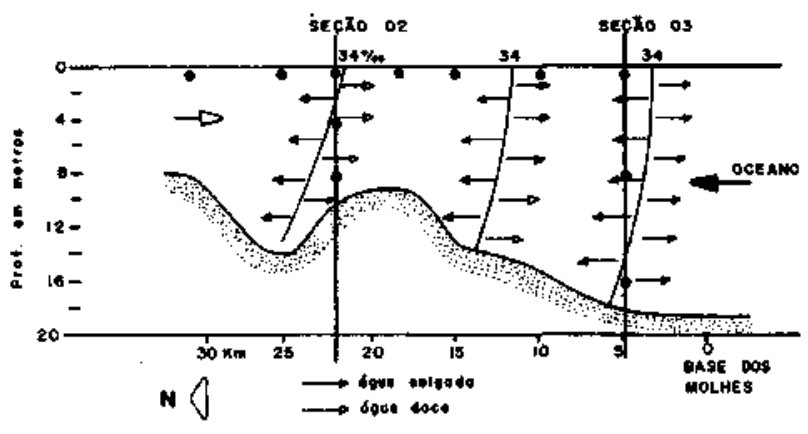

CR. MS 8

EstuARIO: TIPO C tattamante catrotificado

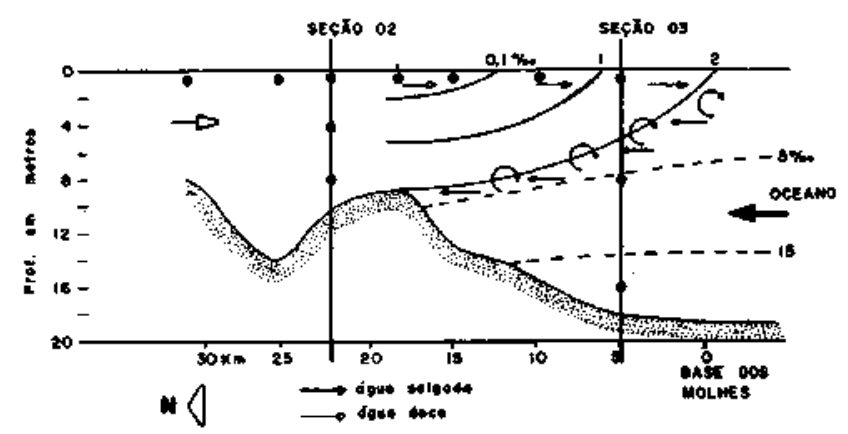

Segundo Rusnak (1967), as taxas de acumulação de sedimentos da bacia dependem não-somente do suprimento extemo e da posição geográfica, como também do clima local. Em regiões úmidas, com grandes rios, a taxa é mais elevada, citando como exemplo o Amazonas e o Mississipi; em regiões áridas, tende a ser muito baixa, pelo suprimento de material ter origem eólica e também provir do oceano.

A maioria dos estuários de clima temperado com fluxo moderado estão dentro da primeira categoria. No entanto, se o fluxo é deficiente por alguma razão, o estuário se caracterizará pela acumulação negativa. Estes são mais comuns em regiões semi-áridas.

A região estudada, de acordo com a estação do ano, pode ser enquadrada no tipo 1 (inverno e primavera) ou no tipo 3 (verão e outono). Grande parte do material proveniente dos rios, principalmente do Complexo Guaíba, é depositado no corpo lagunar, num processo de sedimentação seletiva, do norte para o sul, dos mais grossos aos mais finos. A fração fina, representada por siltes e argilas, é na sua maior parte exportada para o oceano através da desembocadura.

Observações recentes sobre a granulometria do material em suspensão das águas superficiais da Laguna dos Patos indicam como sendo $85 \%$ constituído de silte, $10 \%$ de argila e $5 \%$ ou menos de areia.

Sabe-se que os processos que governam o transporte e a deposição do material em suspensão na desembocadura, bem como as suas concentrações, podem ser associados aos padrões de circulação estuarina. Em casos de pequenas amplitudes de marés, tais processos são governados por gradientes de pressão resultantes da diferença de densidade (costa leste dos E.U.A., Laguna dos Patos), ao contrário do que ocorre

Cค. 154

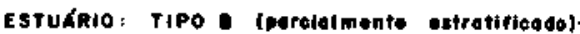

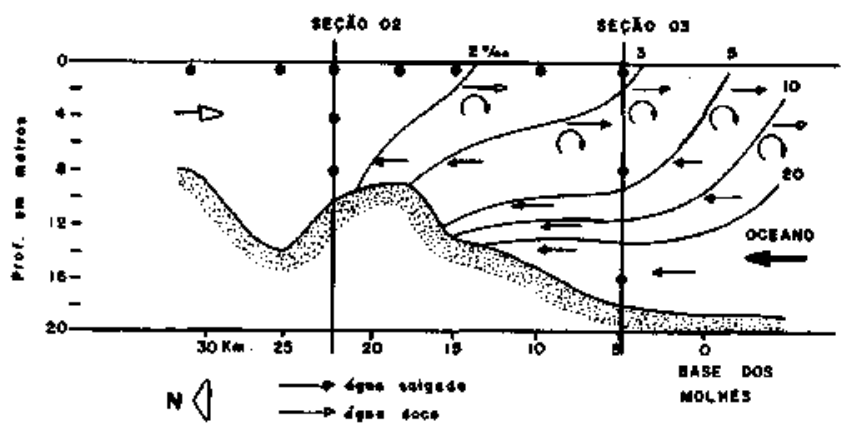

CR. Us 6

ESTUARIO ; TIPO O lounho telind

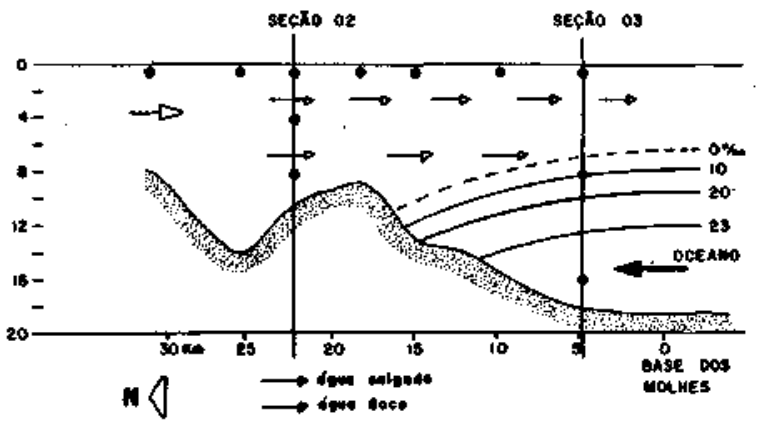

Figura 4 - Modelos de circulação típicos, com base nos quatro tipos apresentados por Cameron \& Pritchard (1963): Cruzeiro MS1 (tipo A); Cruzeiro MS4 (tipo B); Cruzeiro MS8 (tipo C; Cruzeiro MS6 (tipo D)

Figure 4 - Typical circulation patterns, according to the four models presented by Cameron \& Pritchaid (1963): Cruise MS1 (type A); Cruise MS4 (type B); Cruise MS8 (typeX:); Cruise MS6 (type D) 
em estuários europeus que apresentam regime macrotidal (Allen et al 1982).

As situações hidrológicas observadas na desembocadura da Laguna dos Patos, no período de 1982 a 1983, refletem aspectos sazonais dos parâmetros da água, os quais estão muito relacionados com o volume de água que chega à região, e principalmente das condições meteorológicas.

A figura 5 apresenta a variação média do material em suspensão e da salinidade de superfície no período amostrai. As concentrações do material em suspensão se comportaram de maneira desigual em função do aporte de água doce, penetração de água salgada (agregação/floculação/defloculação), e ressuspensão por correntes e/ou ventos. A pequena declividade da bacia $(2 \mathrm{~m}$ em $250 \mathrm{~km})$, a distância do Complexo Guaíba e o atraso do defluxo indicam que as maiores concentrações encontradas na desembocadura não necessariamente coincidem com as épocas de maiores vazões.
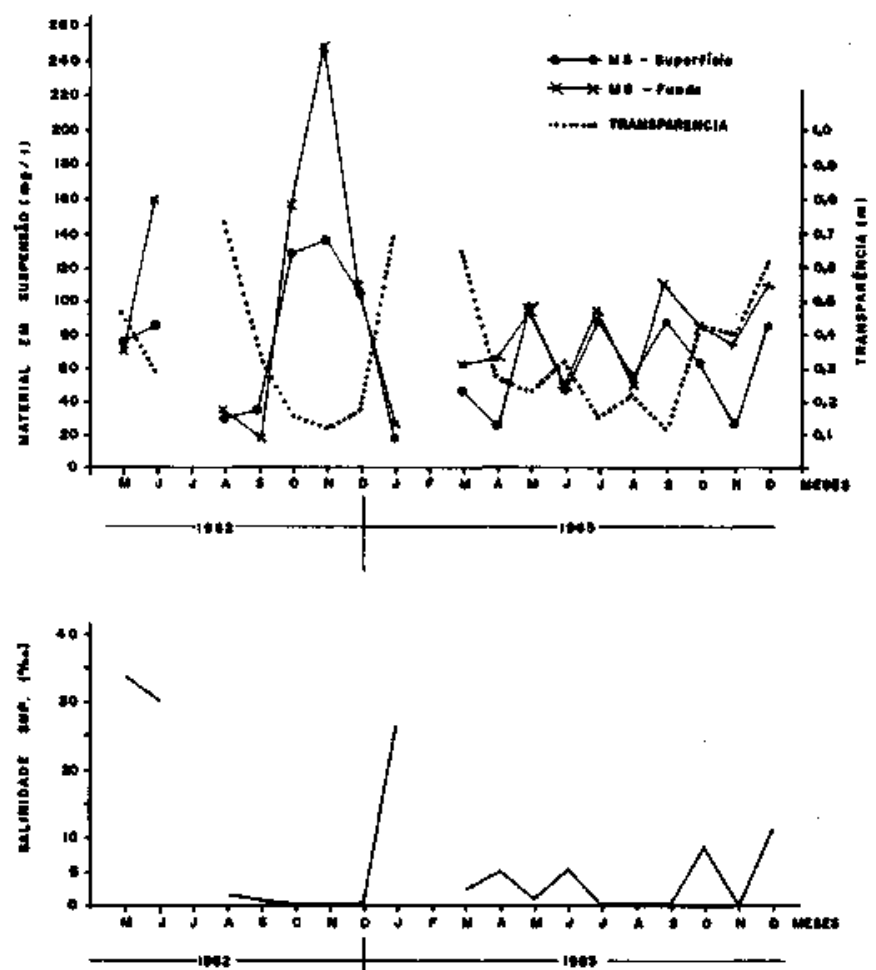

Figura 5 - Variação média do material em suspensão e da salinidade de superfície no período amostrado Figure 5 - Suspended matter and surface salinity mean variation during the sampling period
Balanço preliminar sobre a importação e exportação do material em suspensão De maneira geral, estuários são quantitativamente muito importantes no suprimento de materiais dissolvidos e particulados para os oceanos. Através da desembocadura da Laguna dos Patos, praticamente nenhum trabalho específico foi realizado sobre os totais de sedimentos em suspensão que são exportados para a região costeira. A ausência de dados desta natureza se deve às dificuldades em avaliar as variações de fluxo em geral bi-direcional na área.

Durante os levantamentos realizados, foram obtidos dados in situ que permitiram, ainda que de forma preliminar, avaliar o transporte de material em suspensão naquelas situações específicas, representadas pelos cruzeiros 1, 4,5,6 e 7. Nestes cruzeiros, foi possível determinar a velocidade e a direção do fluxo, e, após calculadas as vazões, estimar o total de material que transitava em suspensão e o total exportado, de acordo com valores encontrados na seção 3 , por ser esta a mais estreita e próxima da barra.

A situação do cruzeiro MS 6 pode ser considerada como um caso particular do encontrado no cruzeiro MS 7, porque o fluxo de entrada é sustado pelo grande aporte de água doce, e neste caso a cunha salina penetrou à distância de $5 \mathrm{~km}$ à montante da seção 3, (Fig. 3).

CONCLUSÕES Da análise dos dados de qualidade da água, ambientais e de interpretação dos resultados das variaçõ̃es espaciais da salinidade, as principais conclusões foram: 1. As condições hidrológicas da área (tipos de estuário) estão associadas aos totais de precipitação e ao fluxo de água doce provenientes das Lagunas dos Patos e Mirim, os quais dependem da direção, duração e força do vento no sistema lagunar e na desembocadura. Porém, podem ocorrer situações de alto fluxo de água doce e ação constante de ventos do quadrante norte coincidentes com o eixo da laguna, descaracterizando o ambiente estuarino presente na maior parte do ano, e constituindo, então, um sistema típico fluvial;

2. As situações hidrológicas verificadas apresentam como regra geral um comportamento sazonal:

\section{Primavera Sem estuário}

Estuário de cunha salina

Estuário parcialmente estratif içado

Estuário verticalmente misturado Estuário verticalmente misturado Estuário parcialmente estratif içado

Inverno Estuário altamente estratificado Sem estuário

Estas situações, entretanto, podem mudar rapidamente (questão de horas), decorrentes das condições meteorológicas (na região da desembocadura).

3. As concentrações de material em suspensão na superfície dependem do aporte de água doce do Canal do São Gonçalo

Tabela 2 - Cruzeiros que apresentaram situações típicas de circulação e taxas de intercâmbio de material em suspensão com a plataforma adjacente. $\boldsymbol{S 1}$. Área da seção 3 com fluxo à jusante; $\boldsymbol{S} \boldsymbol{2}$. Área da seção 3 com fluxo à montante

Table 2 - Cruises that presented typical patterns of circulation and exchange rates of suspended matter with the inner shelf. S1. Area of section 3 showing seaward flow; S2. Area of section 3 showing landward flow

\begin{tabular}{|c|c|c|c|c|c|c|}
\hline \multirow[t]{2}{*}{ Cnuzeiro } & \multirow[t]{2}{*}{ Tipo } & \multicolumn{2}{|c|}{$\begin{array}{c}\text { Velocidade de Corrente } \\
\text { Média } \\
\text { (m/s) }\end{array}$} & \multicolumn{2}{|c|}{$\begin{array}{c}\text { Concentração Média de } \\
\text { Material em Suspensấo } \\
(\mathrm{mg} / \mathrm{l})\end{array}$} & \multirow[t]{2}{*}{$\begin{array}{l}\text { Intercaimbio de Material em } \\
\text { Suspensio com a Plataforma }\end{array}$} \\
\hline & & S1 & $\overline{\mathrm{S} 2}$ & S1 & $\mathbf{S 2}$ & \\
\hline MS 1 & A & - & 0,64 & - & 43,0 & importaçăo 864,0 ton $/ \mathrm{h}$ \\
\hline MS 4 & B & 0,63 & 0,30 & 42,0 & 153,1 & exportaçäo 561,9 ton/h \\
\hline MS 7 & c & 0,44 & 0,33 & 63,8 & 93,0 & exportaçäo 15,6 ton/h \\
\hline MS 6 & D & 0,67 & 0,50 & 115,9 & 196,0 & exportaçăo 999,4 ton/h \\
\hline
\end{tabular}


e da Laguna dos Patos, bem como da ressuspensão por ondas nas partes mais rasas. Junto ao fundo, além dos fatores acima mencionados, estão relacionadas à entrada de água salgada que, dependendo da sua intensidade, pode ressuspender material já depositado, estando também condicionada à precipitação por floculação e agregação das partículas mais finas. As maiores concentrações observadas são devidas à entrada da cunha salina, em cujo limite ocorre a turbidez máxima (Paim \& Moller 1986).

4. A importância que representa o transporte de material para a região costeira, em cada situação considerada (exemplo, cruzeiro $6=999,4$ t/horas), bem como o que entra na desembocadura, fluxo negativo (exemplo, cruzeiro $1=$ 864 t/hora), demonstra a existência de importantes interações estuário-plataforma.
5. Por último, lembramos que apesar dos esforços dispendidos nos últimos anos, concluiu-se que para a realização de estudos que visem quantificar e modelar um ambiente dinâmico como o descrito neste trabalho, é necessário uma aquisição sistemática e simultânea de dados que cubram toda a área, principalmente no que se refere ao monitoramento da salinidade, correntes e condições meteorológicas.

Agradecimentos Os autores agradecem ao dr. Lauro Júlio Calliari pela revisão técnica do manuscrito; ao Conselho mtermiriisterial para Recursos do Mar (CIRM), pelo apoio financeiro aos trabalhos in situ; à tripulação da Lancha Oceanográfica Larus, pelos trabalhos a bordo, e à Fundação de Amparo à Pesquisa do Rio Grande do Sul (FAPERGS), pela bolsa de iniciação científica.

\section{REFERÊNCIAS BIBLIOGRÁFICAS}

ALLEN, G.P.; CASTAING, P.; SALOMON, J.C. 1982. Effet de Ia marée sur les mouvements de l'eau et des sediments dans lês estuaires. Mém. Soe. GéoL Fr., N.S., 144:5-16.

ARNASON, G. 1984. Estuary modeling. In: MATTEWS, S. \& GOLDBERG, G. ed Man's Impact on Terrestrial and Oceans Ecosystems. Massachusetts, the Massachusetts Institut of Technology, v. 1, p. 431-477.

ASMUS, M.L. 1984. Estrutura da Comunidade Associada à Ruppia Marítima no Estuário da Lagoa dos Patos, RS. Rio Grande. 154 p. (Dissertação de Mestrado, FURG).

BORDAS, MP.; BORCHE, A.C.; ALMEIDA, L.E. SÁ B.; SANCHEZ Y VACAS, A. 1984. Circulação e dispersão na Lagoa dos Patos. In: SEMIN. PESQ. LAGOA DOS PATOS, 1. Porto Alegre, 1984. Súmula... Porto Alegre, CIRM. p. 55-57.

BOWDEN, K.F. 1967. Circulation and diffusion. In: LAUFF, G.H. ed Estuaries. Washington, American Association for the Advancement of Science, p. 15-36.

CALLIARI, L.J. 1980. Aspectos Sedimentológicos e Ambientais na Região Estuarial da Lagoa dos Patos. Porto Alegre. 190 p. (Dissertação de Mestrado, UFRGS)

CAMERON, WM. \& PRTTCHARD, D.W. 1963. Estuaries. In: HILL, M.N. ed. The Sea. New York, Wiley \& Sons. v. 2, p. 306-324.

CLOSS, D. 1962. Foraminíferos e tecamebas da Lagoa dos Patos. Boi Esc. Geo., 11:1-130.

DELANEY, PJ.V. 1965. Fisiogrqfia e Geologia de Superfície da Planície Costeira do Rio Grande do SuL Porto Alegre, UFRGS/Escola de Geologia. 104 p. (Publ. Esp. 9).

DEPARTAMENTO MUNICIPAL DE ÁGUAS E ESGOTOS 1974. O Rio Guaiba: Suas Características Físico-Químicas e Biológicas. Porto Alegre, DMAE. p. 1-128. (Rei. Téc. 12).

HARTMANN, C. 1985. Estudo do Material em Suspensão e Dissolvido no Estuário da Laguna dos Patos, RS, Fase // - Maio 82 a Dezembro 83. Rio Grande, FURG/DGEOLOG. 45 p. (ReL Interno).

HARTMANN, C. 1988. Utilização de Dados Digitais do Mapeador Temático Para Obtenção de Padrões de Distribuição do Material em Suspensão na desembocadura da Laguna dos Patos. São José dos Campos. 190 p. (Dissertação de Mestrado, INPE).

HARTMANN, C. 1989. Distribuição do Material em Suspensão e Circulação das Águas na Desembocadura da Laguna dos Patos, RS. Rio Grande. FURG/DGEOLOG. 145 p. (Rei. Interno).
HARTMANN, C; CALLIARI, L.J.; MOLLER, O.O., Jr. 1985. Material em suspensão no estuário da Laguna dos Patos, RS, fase I, observações preliminares, abril 79 a março 80. Sociedade \&. Natureza, 4:73-95.

HARTMANN, C.; SANO, E.E.; PAZ, R.S.; MOLLER JR., O.O. 1986. Avaliação de um período de cheia (junho de 1984) na região sul da Laguna dos Patos, através de dados de sensoriamento remoto, meteorológicos e oceanográficos. In: SIMP. BRAS. SENSOR. REMOTO, 4. Gramado, 1986, Anais... Gramado, INPE. v. 1, p. 685-694.

HERZ, R. 1977. Circulação das Águas de Superfície da Lagoa dos Patos. São Pauto. 261 p. (Tese de Doutorado, IG/USP).

KANTIN, R. 1983. Hidrologie et Qualité dês Eaux de la Region Sud de Ia Lagune dos Patos (Brésil) et de Plate-Forme Continentale Adjacente. Bordeaux. 195 p. (These de Doctorat, Université de Bordeaux-I).

MOLLER, O.O., Jr.; PAIM, P.S.G.; HARTMANN, C. 1984. Material em suspensão na região estuarina da Laguna dos Patos, RS, Brasil. In: SEMIN. PESQ. LAGUNA DOS PATOS, 1. Porto Alegre, 1984 Súmula... Porto Alegre, CIRM. p. 85-90.

MOLLER, O.O., Jr.; PAIM, P.S.G.; SOARES, J.D. 1989. Facteurs et mécanismes de la circulation dês eaux dans 1'Estuaire de la Lagune dos Patos (Brésil). Bulletim Informatifdu Bassin d'Aquitaine, (no prelo).

OTMAN, F. 1964. Une nouvellebouteillehorizontale. Marine Geology. 3(1):7 p. (Short comunication).

PAIM, P.S.G. \& MOLLER, O.O., Jr. 1986. Material em Suspensão e Dissolvido no estuário da Laguna dos Patos, fase III. Rio Grande, FURG/DGEOLOG. 150 p. (ReL Interno).

PAZ, R.S. 1984. Aspectos meteorológicos da Lagoa dos Patos, RS. In: SEMIN PESQ. LAGOA DOS PATOS, 1. Porto Alegre, 1984. Súmula... Porto Alegre, CIRM. p. 79-81.

PRITCHARD, D. W. 1967. What is a estuary. Physical viewpoint. In: LAUFF, G. H. ed Estuaries. Washington, American Association for the Advance of Science, p. 3-5.

RUSNAK, G.A. 1967. Rates of sediment accumulation in modern estuaries. In: LAUFF, G.H. ed Estuaries. Washington, American Association for the Advance of Science, p. 180-184.

MANUSCRITO A702

Recebido em 2 de maio de 1991

Revisão do autor em 9 de outubro de 1991

Revisão aceita em 30 de outubro de 1991 